\title{
Difficulties of Total Knee Arthroplasty on Maquetand Previous Tibial ValgusOsteotomy
}

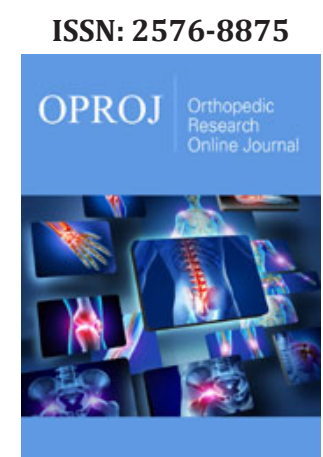

*Corresponding author: Martínez Municio G,University of Valladolid, Spain

Submission: 眥 November 24, 2020

Published: 毕 December 17, 2020

Volume 7 - Issue 5

How to cite this article: Martínez Municio $G^{*}$, Trigueros Larrea JM, González Bedia MA, Vaca Fernández PL, Chávez Valladares S, Vega Castrillo A. Difficulties of Total Knee Arthroplasty on Maquetand Previous Tibial ValgusOsteotomy. Ortho Res Online J. 7(5). OPROJ. 000672. 2020. DOI: 10.31031/OPROJ.2020.07.000672

Copyright@: Martínez Municio G, This article is distributed under the terms of the Creative Commons Attribution 4.0 International License, which permits unrestricted use and redistribution provided that the original author and source are credited.

\author{
Martínez Municio G*, Trigueros Larrea JM, González Bedia MA, Vaca Fernández \\ PL, Chávez Valladares S, Vega Castrillo A \\ University of Valladolid, Spain
}

\section{Introduction}

The tibial osteotomy constitutes a treatment of proven efficacy to delay the appearance of osteoarthritis in the medial compartment, but not the Maquet operation or advancement of the tibial tuberosity that is practically in disuse at the present time. However, these interventions make the subsequent implantation of a Total Knee Prosthesis extremely difficult.

\section{Clinical Case}

A 70-year-old man who underwent partial meniscectomy of the left knee and Maquet and right knee valgus osteotomy who presented with right knee pain that worsens when kneeling and climbing stairs with limited walking function [1]. On examination, he presented positive Zohllen, pain in the medial interline, no ligamentous yawning and limited mobility $-10^{\circ} / 90^{\circ}$.

\section{Radiography}

Tricompartmental gonarthrosis on osteotomy. The patient is proposed to place a TKR. During surgery, a very low patella with large retropatellar fibrosis was observed, as well as increased tibial slope. A single radius Postero-Stabilized (PS) TKR with posterior reference is implanted with a cemented short tibial stem and $11 \mathrm{~mm}$ polyethylene [2]. At three months, anterior knee pain persists with a feeling of instability when going up and down stairs and getting up from the chair, articular balance of $0^{\circ}$ / $120^{\circ}$. At 6 months, instability, pain, and symmetrical laxity continues, predominantly in flexion. For this reason, it was decided to change the polyethylene to a total stabilized one (TS) of $16 \mathrm{~mm}$. The evolution of the patient is satisfactory, presenting an extension of $-5^{\circ}$ and flexion of $120^{\circ}$ at six postoperative months, without pain, and the knee is stable. Five years later, the patient continues without pain, with good mobility and stability of both knees, and without signs of loosening [3].

\section{Discussion}

The importantalteration in the tibial anatomy that occurs after performing the osteotomies makes the ligamentous balance very difficult, so in these cases the use of navigation or a revision prosthesis that allows greater intraoperative versatility [4]. The follow-up of these patients is essential and, given the appearance of instability, early reoperation is very important (Figures 1-5).

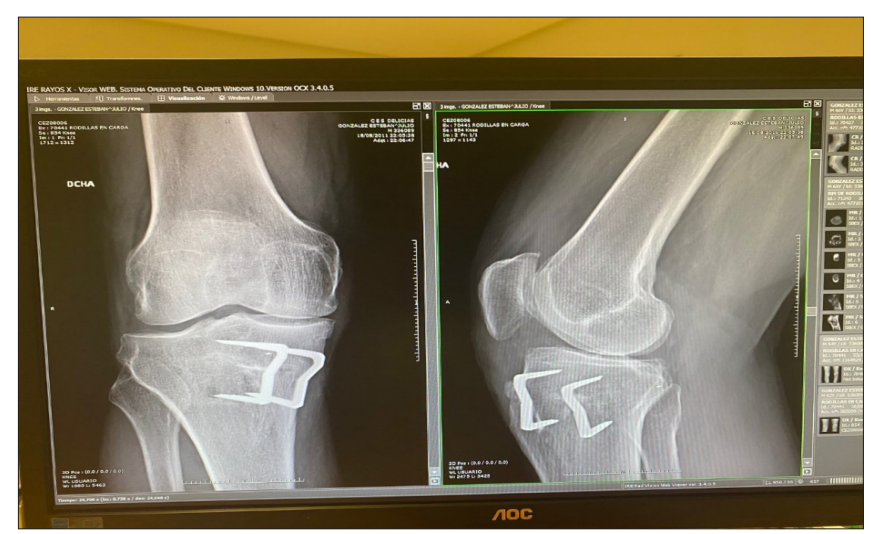

Figure 1: AP and Lateral X-ray of the right knee upon arrival for consultations. 


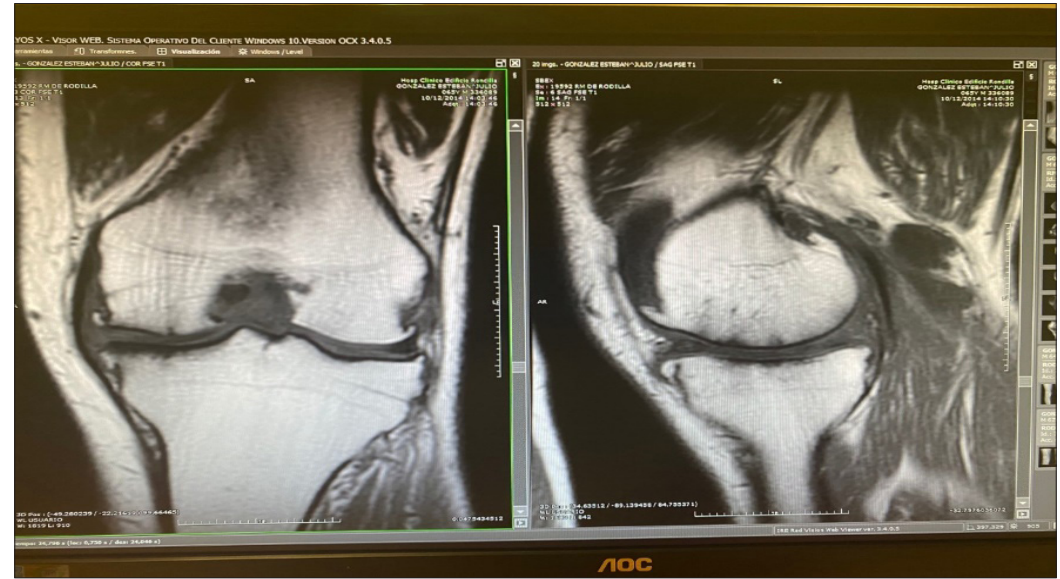

Figure 2: Magnetic resonance imaging of the knee: tricompartmental knee osteoarthritis.

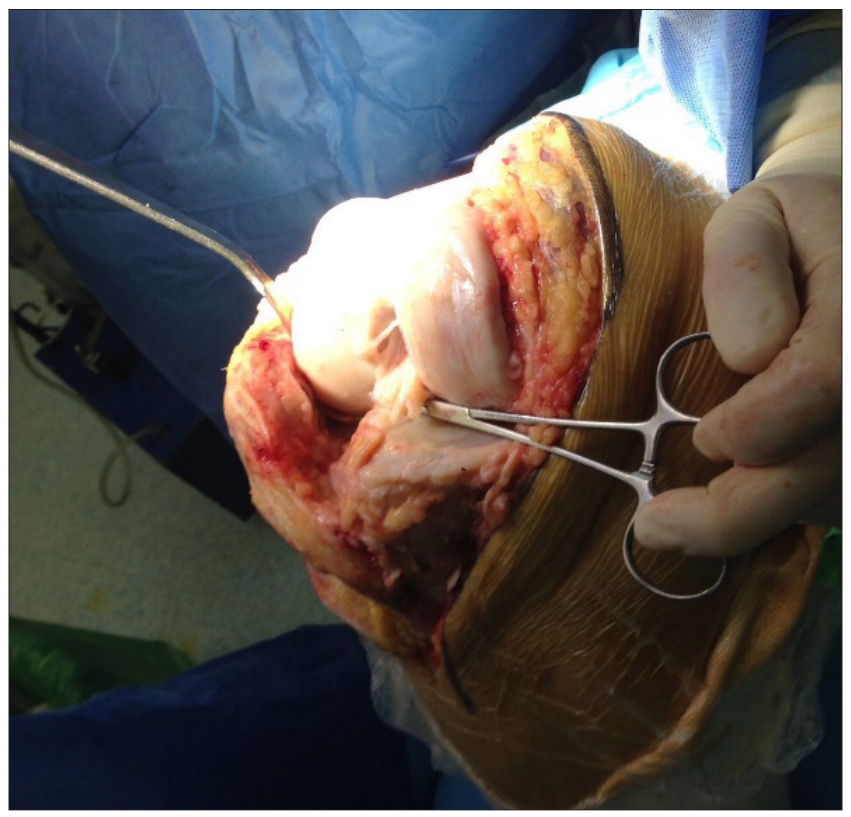

Figure 3: Intraoperative photograph: see low patella.

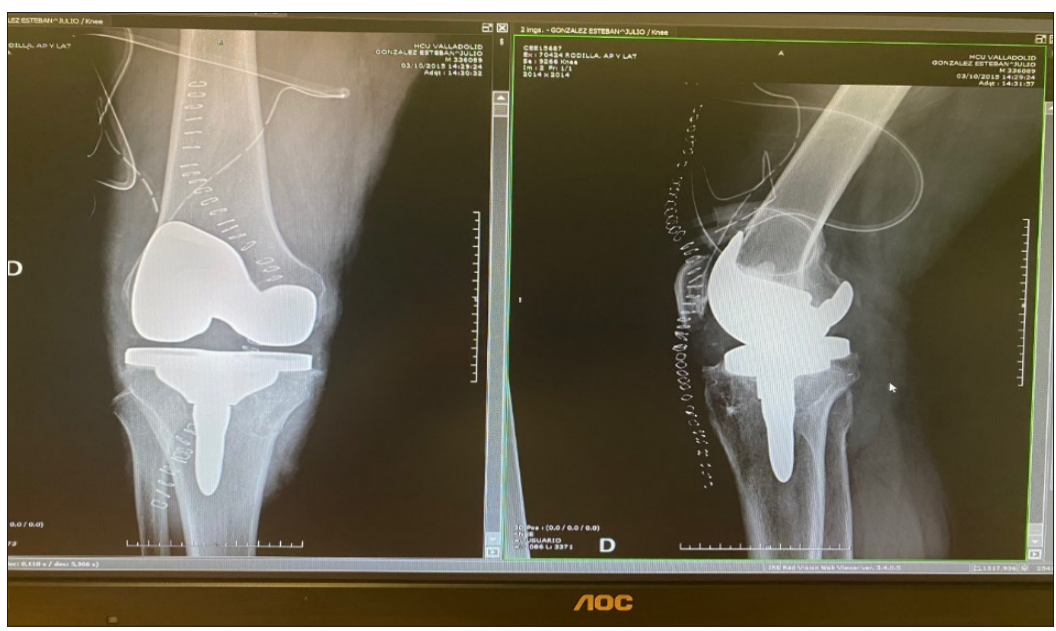

Figure 4: Post-operative control X-ray removal of staple and total knee arthroplasty. 


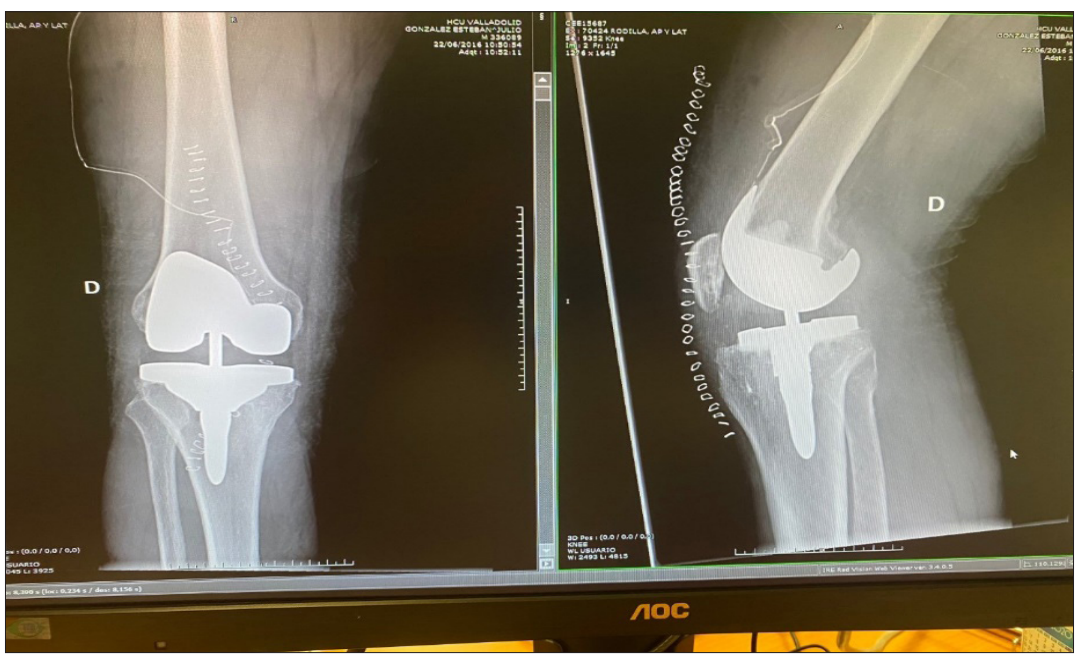

Figure 5: Post-operative control x-ray polyethylene replacement TS.

\section{References}

1. Fonseca F, Oliveira JP, Marques P (2013) Maquet III procedure: what remains after initial complications..long term results. J Orthop Surg Res 1: 8-11.

2. Abdel Megied WS, Mahran MA (2010) The new dual osteotomy: combined open wedge and tibial tuberosity anterorisation osteotomies. Int Orthop Feb 34(2): 231-237.

3. Madan S, Ranjith RK, Fiddian NJ (2003) Total knee replacement following high tibial osteotomy. Bull Hosp Jt Dis 61(1-2): 5-10.

4. Noda T, Yasuda S (2000) Clinico radiological study of total knee arthroplasty after high tibial osteotomy. J Orthop Sci 5(1): 25-36. 